\title{
Celiac Disease: A Progress Report
}

Donald A. Antonioli, M.D.

Department of Pathology, Beth Israel Deaconess Medical Center and Harvard Medical School, Boston, Massachusetts

Celiac disease (CD) has a wide range of clinical presentations and is being diagnosed with increasing frequency in patients in the 4th and 5th decades of life. The diagnosis of $C D$ is confirmed by a combination of clinical, serological, and morphological findings associated with a response to a gluten-free diet. In small-bowel mucosal biopsy specimens, abnormalities range from minimal (increased villous intraepithelial lymphocytes only) to severe (complete villous blunting with crypt hyperplasia). Recognition of $\mathrm{CD}$ is important because appropriate therapy of this condition will obviate the risk of its severe complications.

KEY WORDS: Celiac disease, Gluten-sensitive enteropathy, Malabsorption.

Mod Pathol 2003;16(4):342-346

Celiac disease (CD; gluten-sensitive enteropathy) is a condition in which individuals with a genetic predisposition exhibit increased immunological responsiveness to prolamins such as dietary wheat gliadin and similar proteins in barley, rye, and (possibly) oats. Diagnosing CD is important for several reasons:

- Based on the results of recent prospective investigations, $\mathrm{CD}$ is a common disease that may affect as many as 1:200 to 1:300 people in Western countries;

- Untreated CD is associated with a wide variety of symptoms and signs, morbidity, and, occasionally, death secondary to neoplastic complications;

- Treatment with a gluten-free diet, usually for the patient's lifetime, reverses the clinical abnormalities and also seems to prevent the malignant complications (1-3).

Copyright () 2003 by The United States and Canadian Academy of Pathology, Inc.

VOL. 16, NO. 4, P. 342, 2003 Printed in the U.S.A.

Date of acceptance: January 8, 2003.

Address reprint requests to: Donald A. Antonioli, M.D., Department of Pathology, Beth Israel Deaconess Medical Center, 330 Brookline Avenue, Boston, MA 02215; fax: 617-975-5620; e-mail: dantonio@caregroup.harvard.edu. DOI: 10.1097/01.MP.0000062997.16339.47

\section{CLINICAL FINDINGS}

The classic presentation of CD is a severe malabsorption syndrome with diarrhea, steatorrhea, and weight loss. Because the onset of classic cases is typically in childhood, failure to thrive is a major presenting complaint. However, as a result of recent serological and biopsy investigations, it has become clear that CD may be a more subtle disease, with protean manifestations, that is first diagnosed in early adulthood or later. In fact, in some series, about $25 \%$ of patients ultimately shown to have $\mathrm{CD}$ are diagnosed after the age of 45 to 50 years. The major clinical findings in atypical, "lateonset," or latent CD include short stature, infertility, peripheral neuropathies, iron and/or folate deficiency, osteoporosis, recurrent abdominal pain (children), "indigestion" (adults), and dental enamel defects; diarrhea is usually minimal or absent, and malabsorption is detected only by specific testing (1-10). In addition, CD has recently been suggested to be the actual cause of symptoms in some patients diagnosed with irritable bowel syndrome $(11,12)$.

If untreated, CD (whether florid or subtle) is associated with serious long-term complications. In comparison to control populations, the following abnormalities have been defined:

- Increased risk of esophageal squamous cell carcinoma (perhaps related to a deficiency of trace metals such as zinc) $(1-3,13-15)$;

- Increased risk of primary small-bowel adenocarcinomas (1-3, 13-15);

- Increased risk for the development of nonHodgkin lymphoma, in particular enteropathy-type T-cell lymphoma. The latter neoplasm is virtually confined to patients with CD, many of whom have had a short adult-onset course of CD. This T-cell lymphoma may manifest itself as "refractory sprue." In its evolution, enteropathy-type T-cell lymphoma first features small-bowel lymphoepithelial lesions in a background of celiac-type histology. Neoplastic progression is characterized by ulcerative jejunitis and, ultimately, frank lymphoma 
with bowel mural masses, obstruction, and hemorrhage. The morphology of the clonal $\mathrm{T}$ cells is highly variable, with small cell, large cell, and mixed forms. The clinical course is typically short $(13,15-19)$.

As noted earlier, a strict gluten-free diet implemented for $>5$ years seems to eliminate the risk for these neoplasms (14).

Other lesions associated with untreated CD include lymphocytic gastritis and lymphocytic colitis. Although the prevalence of these two conditions in patients with newly diagnosed CD is as yet unclear, their development signifies a diffuse intestinal susceptibility to gluten-induced damage (20-23). For example, in patients with $\mathrm{CD}$ and lymphocytic gastritis, the gastric mucosa will revert to or toward normal upon institution of a gluten-free diet (20).

Another associated lesion is dermatitis herpetiformis $(\mathrm{DH})$, a pruritic, papulovesicular skin lesion that is symmetrically distributed on scalp, buttocks, and extremities. It is characterized by a granular deposition of IgG at the epidermal-dermal junction. Most (70-90\%) of patients with DH will have a severe mucosal lesion on small-bowel biopsy; conversely, $\sim 10 \%$ of patients with $\mathrm{CD}$ will develop $\mathrm{DH}$ at some point in their clinical course. The skin lesions resolve when the patient is placed on a gluten-free diet $(1-3,22,24)$.

Finally, some immune disorders appear to be associated with CD: selective IgA deficiency, insulin-dependent diabetes mellitus, Sjogren's syndrome, and autoimmune thyroiditis $(1-3,25)$.

\section{PATHOGENESIS}

The pathogenesis of CD is as yet not fully elucidated. There is genetic susceptibility; patients with CD have a predominance of HLA Class II DQ2 and/or DQ8 molecules. Gliadin-derived peptides are processed by HLA Class II molecules for presentation to helper $\mathrm{T}$ cells in susceptible mucosa that has perhaps been primed by a triggering effect (such as adenovirus 12 infection). Helper T cells are activated and orchestrate changes leading to enteropathy, including the invasion of the surface epithelium by CD8 T-cells. Also proposed is a component of early direct gliadin toxicity on enterocytes, resulting in stimulation of HLA molecules in enterocytes and subjacent macrophages $(1-3,26,27)$.

Transglutaminase is a normal gut enzyme that is released during injury and stabilizes the crosslinking of proteins in granulation tissue. Gliadin and transglutaminase link to form a neoepitope that becomes the target of an antibody response. Thus, CD represents a complex array of cellular and humoral immune responses. Transglutaminase has recently been identified as the epitope recognized by the antiendomysial antibody, a sensitive and specific marker of CD (see "Diagnosis" section of this article; 26, 28-30). Elimination of gliadin stops the direct mucosal injury and eliminates the substrate necessary to form the neoepitope that propagates immunologically mediated damage $(2,30)$.

\section{DIAGNOSIS}

The gold standard of diagnosis remains the small-bowel mucosal biopsy (1-3). As will be seen in the next section, the small-bowel mucosa may show a range of abnormalities from minimal to severe. With increased awareness of $C D$ as a cause of subtle symptoms and signs, serologic screening for $\mathrm{CD}$ is now frequently performed. The most sensitive and specific profile for $\mathrm{CD}$ is detection of antitransglutaminase and IgA antiendomysial antibodies. Because upwards of $3 \%$ of CD patients are also IgA deficient, this cohort will demonstrate false-negative antiendomysial antibody testing. IgG antigliadin autoantibodies are also detected in CD patients, but they are less specific than the other antibodies just discussed, being present in other intestinal inflammatory diseases $(31,32)$.

The diagnosis of CD is supported by an unequivocal response to a gluten-free diet, with decreasing antibody titers and a repeat mucosal biopsy showing reversal of the histologic finding toward or to a normal appearance. However, histologic remission may take several years to occur and generally is more protracted in adults than in children (28-30, 33). Gluten rechallenge is now seldom performed and is limited to infants and children in whom cow milk protein allergy or intolerance is a confounding variable, or to patients with an equivocal first biopsy and/or equivocal response to gluten restriction (10).

\section{PATHOLOGY}

At endoscopy, the appearance of the duodenal mucosa will vary depending on the severity of the $\mathrm{CD}$. Latent CD typically demonstrates no gross abnormality and demonstrates normal semicircular folds. With overt disease, the folds may show a scalloped, or notched, appearance; in severe disease, the folds may be decreased in size and number or be completely absent (34). A mosaic pattern of blood vessels may also be evident in severe CD. However, some patients with histologically severe CD have normal-appearing mucosa at endoscopy, and scalloping of semicircular folds is being reported with many non-CD causes of duodenitis (35-37).

As the clinical and endoscopic spectrum of CD has broadened, the range of histologic findings compatible with the diagnosis of serologically positive CD has also increased: 
- Increased intraepithelial lymphocytes (IEL; Fig. 1). This is the first and most sensitive marker of the effects of gluten on the smallbowel mucosa; thus, it is the major histological feature of CD. An increase is defined as $>40$ lymphocytes per 100 surface or upper-crypt enterocytes. The vast majority are $\mathrm{CD} 2+$, CD3+; 70 to $90 \%$ are CD8+ T-cells. In latent forms of CD, an increase in IELs is often the only abnormality; villous architecture and lamina propria cellularity are within the normal range (38-40). IEL counts should be performed on well-oriented villi in sections cut at 3- to 4- $\mu \mathrm{m}$ thickness. Goldstein and Underhill (40) have suggested that a clustering of lymphocytes $(\geq 12)$ in the epithelium at the tips of villi and extending evenly down along the sides of the villus are a clue that CD may be present.

- Increased cellularity in the lamina propria. In CD with villous/crypt abnormalities, plasma cells, lymphocytes, and eosinophils are increased in number, particularly in the upper half of the mucosa. The number of eosinophils

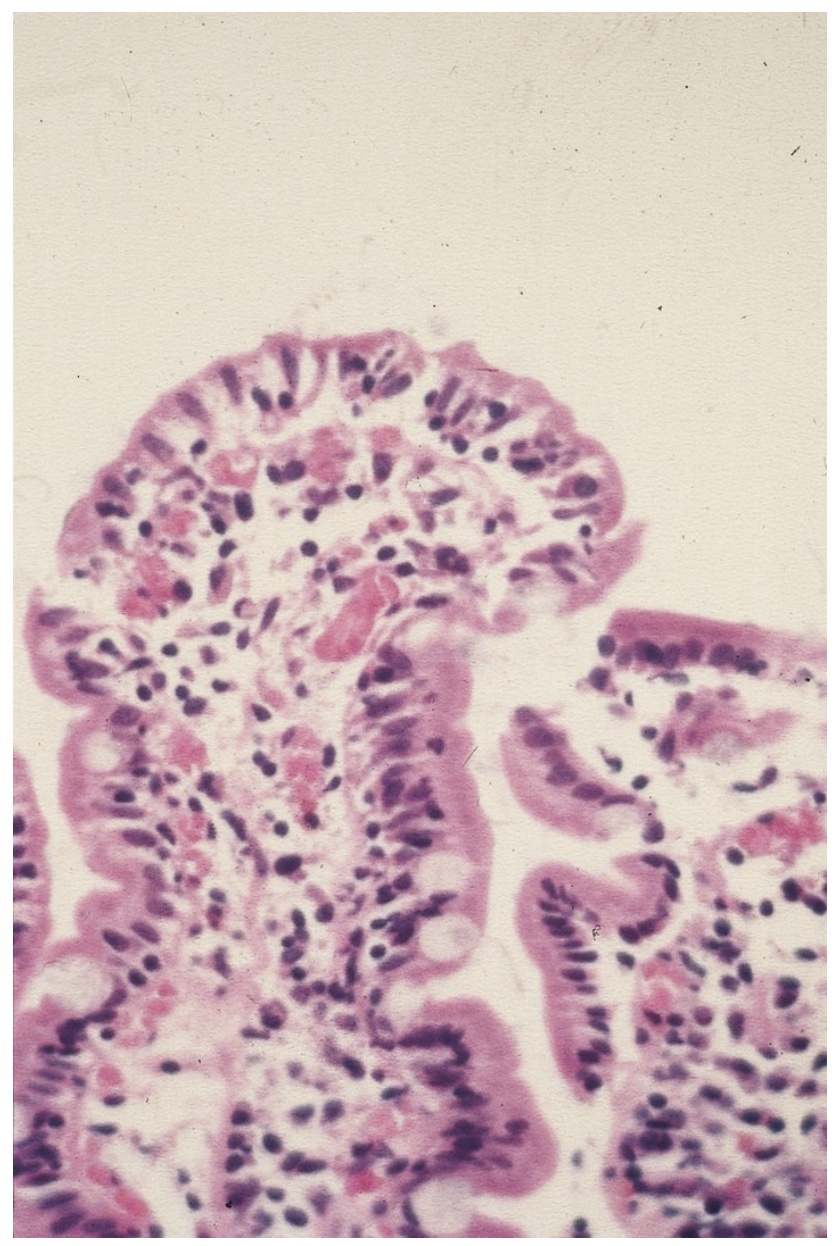

FIGURE 1. Marsh Type I lesion. The villus is unremarkable except for a modest increase in intraepithelial lymphocytes, particularly at the villous tip. may be striking; however, their increase is paralleled by the increase in mononuclear inflammatory cells, a finding that is against a diagnosis of allergic enteritis. Neutrophils are also part of the inflammatory response and may be numerous in the lamina propria $(1-3,39)$. However, if they are associated with cryptitis or crypt abscesses, an alternative diagnosis (such as autoimmune enteropathy, peptic injury, or Crohn's disease) should be considered.

- Enterocyte damage (Fig. 2). In latent or minimal-deviation CD, the enterocytes are unremarkable. With severe injury, however, the apical cytoplasm is typically vacuolated; the cells themselves are shorter than normal and easily dislodged from the underlying basement membrane $(1-3,38,39)$.

- Villous atrophy/crypt hyperplasia (Fig. 2). These changes represent severe damage and can only be assessed in well-oriented sections (39). As a rule, villous-crypt ratios can be assessed if four or more crypts in parallel, nontangential array adjacent to one another can be identified in the biopsy specimen. Taking deeper sections through the tissue block may uncover such areas. Also, it should be recalled
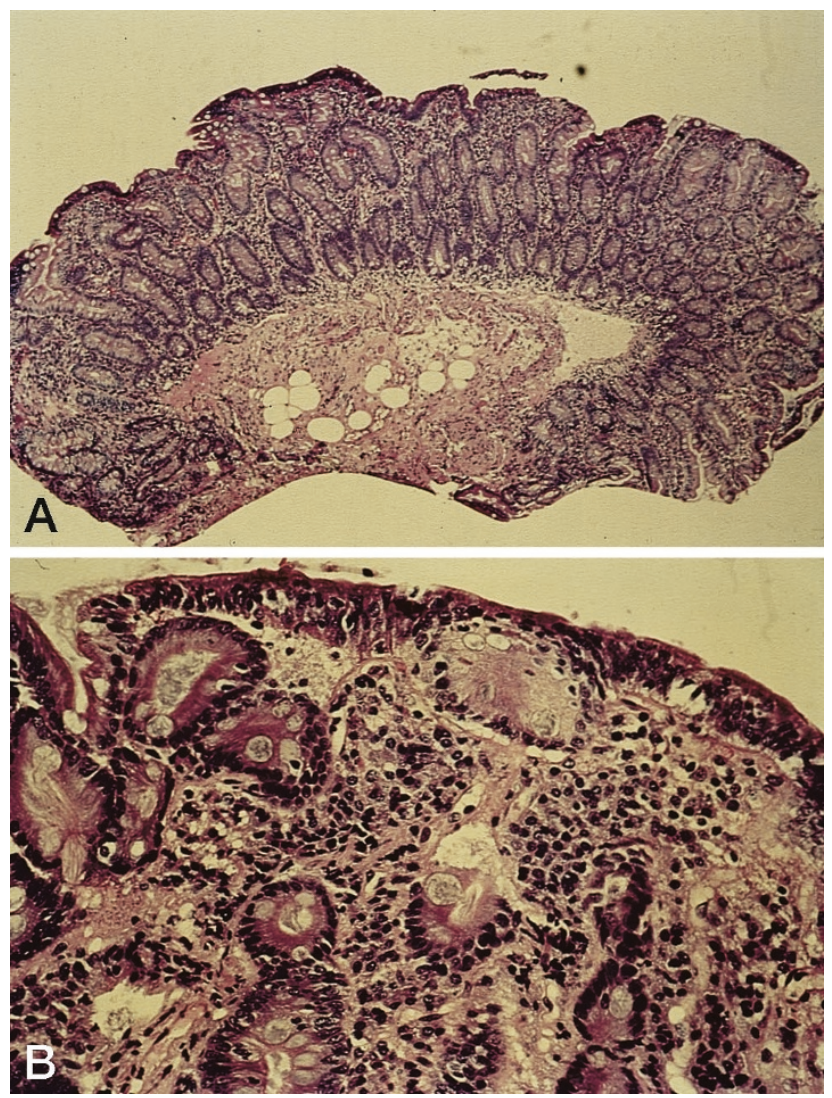

FIGURE 2. Marsh Type III lesion. A, at low power, there is virtually complete villous blunting associated with crypt hyperplasia. B, at higher power, the increased number of surface intraepithelial lymphocytes and the damage to enterocytes are evident. 
TABLE 1. Modified Marsh Classification of CD

\begin{tabular}{cccc}
\hline Marsh Type & $\begin{array}{c}\text { Intraepithelial } \\
\text { Lymphocytes per } \\
\text { 100 Enterocytes }\end{array}$ & Crypts & Villi \\
\hline 0 & $<40$ & Normal & Normal \\
1 & $>40$ & Normal & Normal \\
2 & $>40$ & Increased & Normal \\
$3 \mathrm{a}$ & $>40$ & Increased & Mild atrophy \\
$3 \mathrm{~b}$ & $>40$ & Increased & Marked atrophy \\
$3 \mathrm{c}$ & $>40$ & Increased & Absent \\
\hline
\end{tabular}

Type 0: Normal mucosa; CD highly unlikely.

Type 1 (Infiltrative lesion): Seen in patients on a gluten-free diet (suggesting minimal amounts of gliadin are being ingested); patients with DH; and family members of patients with CD. However, these patients need to be followed because they may convert to a Type 3 lesion.

Type 2 (Hyperplastic type): Very rare; seen occasionally in $\mathrm{DH}$.

Type 3 (Destructive lesion): Spectrum of changes seen in symptomatic CD $(38,39)$.

that villi overlying and adjacent to lymphoid nodules/follicles are normally blunted or absent, and such areas should not be chosen for analysis.

All of these changes may be focal; therefore, a single biopsy may give false-negative results. Diagnostic yield is increased with a larger number of specimens (up to four). If only a single specimen is received, obtaining multiple levels may reveal areas of abnormal mucosa (39).

As can be seen from this discussion, the histologic spectrum of changes in $\mathrm{CD}$ is as varied as the clinical presentation. These morphologic findings have been codified in a modification of Marsh's original classification (39; Table 1)

Refractory $C D$ refers to the case of those patients considered to have CD who stop responding clinically and histologically to a gluten-free diet. Possible causes for refractory CD include the unrecognized intake of gluten, lack of adherence to a gluten-free diet, and the development of lymphoma (3). Patients who have never responded to a glutenfree diet most likely do not have CD (41). The pathologic features of refractory CD are not well defined; possible findings include the development of a thickened subepithelial collagen layer, mucosal thinning and subcryptal mononuclear inflammation, and evidence of lymphoma $(19,42)$.

\section{DIFFERENTIAL DIAGNOSIS}

The combination of clinical, serologic, and histologic findings plus response to a gluten-free diet confirms the diagnosis of CD in most patients. On biopsy, however, some other conditions can mimic aspects of CD. Some of these conditions and useful differential diagnostic points are summarized here:

- Autoimmune enteropathy: crypt injury/destruction; anti-enterocyte antibodies in $50 \%$ of cases. Onset usually in the first 6 months after birth.

- Tropical sprue: lack of antiendomysial antibodies; response to antibiotic and folate therapy.

- Common variable immunodeficiency: paucity or absence of plasma cells; marked lymphoid nodular hyperplasia; Giardia infection common.

- Infectious (usually viral) enteritis: normal IEL counts.

- Food protein intolerance (eggs, cow milk, etc.): increased eosinophils; other allergic manifestation (asthma, atopy); response to elimination diets.

- Development of lymphoma: atypical lymphoid infiltrate; high index of suspicion; imaging studies that demonstrate mass lesions.

\section{REFERENCES}

1. Case records of the Massachusetts General Hospital (Case 5-2001). N Engl J Med 2001;344:510-7.

2. Maki M, Collin P. Coeliac disease. Lancet 1997;349:1755-9.

3. Trier JS. Diagnosis of celiac sprue. Gastroenterology 1998; 115:211-6.

4. Dickey W, Hughes D. Prevalence of celiac disease and its endoscopic markers among patients having routine upper gastrointestinal endoscopy. Am J Gastroenterol 1999;94:2182-6.

5. Green PHR, Shane E, Rotterdam H, Forde KA, et al. Significance of unsuspected celiac disease detected at endoscopy. Gastrointest Endosc 2000;51:60-5.

6. Nehra V. New clinical issues in celiac disease. Gastroenterol Clin N Am 1998;27:453-65.

7. Not T, Horvath K, Hill ID, et al. Celiac disease in the USA: high prevalence of antiendomysial antibodies in healthy blood donors. Scand J Gastroenterol 1998;33:494-8.

8. Rostami K, Mulder CJJ, vanOverbeek FM, et al. Should relatives of coeliacs with mild clinical complaints undergo a small-bowel biopsy despite negative serology? Eur J Gastroenterol Hepatol 2000;12:51-5.

9. Troncone R, Greco L, Mayer M, et al. Latent and potential celiac disease. Acta Paediatr 1996;412:10-4.

10. Walker-Smith JA, Guandalini S, Schmitz J, et al. Revised criteria for the diagnosis of coeliac disease. Arch Dis Child 1990;65:909-11.

11. Sanders DS, Carter MJ, Hurlstone DP, et al. Association of adult coeliac disease with irritable bowel syndrome: a casecontrol study in patients fulfilling ROME II criteria referred to secondary care. Lancet 2001;358:1504-8.

12. Wahnschaffe U, Ullrich R, Riechen EO, Schulzke JD. Celiac disease-like abnormalities in a subgroup of patients with irritable bowel syndrome. Gastroenterology 2001;121:132938.

13. Ferguson A, Kingstone K. Coeliac disease and malignancies. Acta Paediatr 1996;412:78-81.

14. Holmes GKT, Prior P, Lane MR, et al. Malignancy in coeliac disease-effect of a gluten-free diet. Gut 1989;30:333-8.

15. Wright DH. The major complications of celiac disease. Baillieres Clin Gastroenterol 1995;9:351-69.

16. Carbonnel F, Grollet-Bioul L, Brouet JC, et al. Are complicated forms of celiac disease cryptic T-cell lymphomas? Blood 1998;92:3879-86.

17. Corrao G, Corazza R, Bagnardi V, et al. Mortality in patients with coeliac disease and their relatives: a cohort study. Lancet 2001;358:356-61. 
18. Catassi C, Fabiani E, Corrao G, et al. Risk of non-Hodgkin lymphoma in celiac disease. JAMA 2002;287:1413-9.

19. O'Malley DP, Gulley ML, Banks PM. Enteropathy-type T-cell lymphoma: its relationship to refractory celiac disease. Pathol Case Rev 2002;7:110-6.

20. Alsaigh N, Odze R, Goldman H, et al. Gastric and esophageal intraepithelial lymphocytes in pediatric celiac disease. Am J Surg Pathol 1996;20:865-70.

21. Fine KD, Lee EL, Meyer RL. Colonic histopathology in untreated celiac sprue or refractory sprue: is it lymphocytic colitis or colonic lymphocytosis? Hum Pathol 1998;29:1433-40.

22. Holmes GKT. Non-malignant complications of coeliac disease. Acta Paediatr 1996;412:68-75.

23. Wolber R, Owen D, Freeman H. Colonic lymphocytosis in patients with celiac sprue. Hum Pathol 1990;21:1092-6.

24. Koop I, Ilchmann R, Izzi L, et al. Detection of autoantibodies against tissue transglutaminase in patients with celiac disease and dermatitis herpetiformis. Am J Gastroenterol 2000; 95:2009-14.

25. Ventura A, Magazzu G, Greco L. Duration of exposure to gluten and risk for autoimmune disorders in patients with celiac disease. Gastroenterology 1999;117:297-303.

26. Godkin A, Jewell D. The pathogenesis of celiac disease. Gastroenterology 1998;115:206-10.

27. Greco L, Romino R, Coto I, et al. The first large populationbased twin study of celiac disease. Gut 2002;50:624-8.

28. Dieterich W, Laag E, Schöpper H, et al. Autoantibodies to tissue transglutaminase as predictors of celiac disease. Gastroenterology 1998;115:1317-21.

29. Fotoulaki M, Nousia-Arvanitakis S, Augoustidou-Savvopoulou $\mathrm{P}$, et al. Clinical application of immunological markers as monitoring tests in celiac disease. Dig Dis Sci 1998;44:2133-8.

30. Maki M. Tissue transglutaminase as the autoantigen of coeliac disease. Gut 1997;41:565-6.

31. Bonamico M, Tiberti C, Picarelli A, et al. Radioimmunoassay to detect antitransglutaminase autoantibodies is the most sensitive and specific screening method for celiac disease. Am J Gastroenterol 2001;96:1536-40.

32. Tursi A, Brandimarte G, Giorgetti G, et al. Low prevalence of antigliadin and anti-endomysium antibodies in subclinical/silent celiac disease. Am J Gastroenterol 2001;96: 1507-10.

33. Wahab PJ, Meyer JWR, Mulder CJJ. Histologic follow-up of people with celiac disease on a gluten-free diet: slow and incomplete recovery. Am J Clin Pathol 2002;118:459-63.

34. Corezza GR, Caletti GC, Lazzari R, et al. Scalloped duodenal folds in childhood celiac disease. Gastrointest Endosc 1993; 39:543-5.

35. Bardella MT, Minoli G, Radaelli F, et al. Re-evaluation of duodenal endoscopic markers in the diagnosis of celiac disease. Gastrointest Endosc 2000;51:714-6.

36. Shah VH, Rotterdam H, Kolter DP, et al. All that scallops is not celiac disease. Gastrointest Endosc 2000;51:717-20.

37. Ravelli AM, Tobanelli P, Minelli L, et al. Endoscopic features of celiac disease in children. Gastrointest Endosc 2001;54: 736- 42 .

38. Marsh MN, Crowe PT. Morphology of the mucosal lesion in gluten sensitivity. Baillieres Clin Gastroenterol 1995;9:27393.

39. Oberhuber G, Granditsch G, Vogelsang H. The histopathology of coeliac disease: time for a standardized report scheme for pathologists. Eur J Gastroenterol Hepatol 1999;11:118594.

40. Goldstein NS, Underhill J. Morphologic features suggestive of gluten sensitivity in architecturally normal duodenal mucosal biopsies. Am J Clin Pathol 2001;116:63-71.

41. Biagi F, Corazza GR. Defining gluten refractory enteropathy. Eur J Gastroenterol Hepatol 2001;13:561-5.

42. Robert ME, Ament ME, Weinstein WM. The histologic spectrum and clinical outcome of refractory and unclassified sprue. Am J Surg Pathol 2000;24:676-87. 